\title{
ВЗАИМОСВЯЗЬ ПАРАМЕТРОВ КОМПОЗИТНОГО СОСТАВА ТЕЛА С МАРКЕРАМИ ХРОНИЧЕСКОГО СУБКЛИНИЧЕСКОГО ВОСПАЛЕНИЯ И РЕНАЛЬНОЙ ДИСФУНКЦИИ
}

\author{
Шулькина С.Г., Смирнова Е.Н., Бывальцева Е.П., Скрябина П.Э., Лоран Е.А., Козьменко О.А., Чернуха Т.А., \\ Коновалов В.В.
}

ФГБОУ ВО «ПГМУ им. академика Е.А.Вагнера» МЗ России, Пермь

ЦЕЛЬ: с учетом фенотипа ожирения изучить особенности гормональной активности жировой ткани, композитный состав тела, их ассоциации с маркерами ренальной дисфункции.

МАТЕРИАЛЫ И МЕТОДЫ: в исследование были включены 140 человек с ожирением- средний ин-

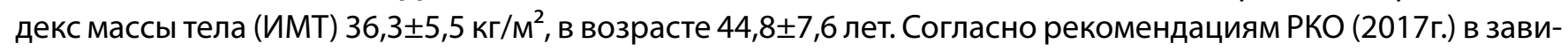
симости от метаболического статуса пациенты были разделены на 2 группы: метаболически здоровый фенотип ожирения (МЗФ) ( $\mathrm{n=50)}$ - пациенты без установленных метаболических нарушений, артериальной гипертензии (АГ) и пациенты с метаболическими нарушениями в сочетании с АГ 1-2 стадии, 1 степени метаболически нездоровый фенотип ожирения (МНЗФ) ( $\mathrm{n}=90)$. В обеих группах отсутствовали признаки

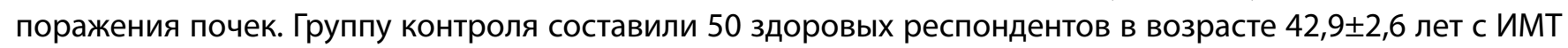
$25,1 \pm 2,3$ кг/м². Композитный состав тела изучали с использованием биоимпедансного анализа анализатором ABC-01 «Медасс». Уровень лептина определяли набором «DBC Канада», инсулина-«Monobind Inc, Германия», резистина — «BioVender, США», цистатина С-сыворотки крови и мочи «BioVendor, Чехия», фактор некроза опухоли- a (TNF-a) и C- реактивный протеин (CRP-hs) в крови -«Вектор-Бест, Новосибирск» методОМ ИФА.

РЕЗУЛЬТАТ: при сравнительном анализе параметров композитного состава тела наибольшие значе-

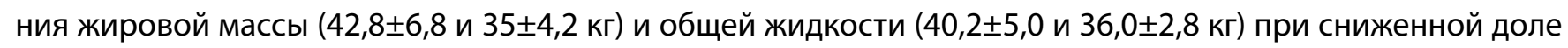
активной клеточной массы (АКМ) $(53,0 \pm 3,2$ и 56,1 $\pm 3,4 \%)$ выявлены у пациентов с метаболически осложненным фенотипом ожирения $(p<0,05)$. Вне зависимости от фенотипа ожирения установлены корреляции: между уровнем диастолического артериального давления (ДАД) и объемом общей $\left(r_{1}=0,42 ; r_{2}=0,52\right)$ и внеклеточной жидкости $\left(r_{1}=0,50 ; r_{2}=0,60\right)$, уровнем ДАД и мочевой экскрецией цистатина $C\left(r_{1}=0,51 ; r_{2}=0,61\right)$ $(p<0,01)$. Снижение доли АКМ в группах ассоциировалось с увеличением уровня резистина $\left(r_{1}=-0,56\right.$; $\left.r_{2}=-0,31\right)$, в группе МНЗФ установлена отрицательная связь доли АКМ с уровнем цитокинов - TNF-a $\left(r_{1}=-0,63\right)$ и CRP-hs $\left(r_{1}=-0,63\right)(p<0,05)$. В группах, вне зависимости от фенотипа, объем жировой массы был связан с уровнем лептина $\left(r_{1}=0,52 ; r_{2}=0,42\right)$ и индексом свободного лептина ( $\left.F L I\right)\left(r_{1}=0,75 ; r_{2}=0,46\right)(p<0,05)$. В группе МНЗФ дополнительно установлена положительная корреляция объема жировой массы с показателями систолического артериального давления (САД) $\left(r_{1}=0,70\right)$ и ДАД $\left(r_{1}=0,65\right)$, с уровнем мочевой кислоты $\left(r_{1}=0,57\right)$, липопротеидами низкой плотности $\left(r_{1}=0,52\right)$, цистатина С в моче $\left(r_{1}=0,75\right)$ и индексом инсулинорезистентности (HOMA-IR) $\left(r_{1}=0,65\right)(p<0,01)$.

ВЫводы: у больных с ожирением, вне зависимости от фенотипа, снижение доли активной клеточной массы сопряжено с увеличением уровня адипоцитокинов. Увеличение объема общей и внеклеточной жидкости, ассоциируется с повышением уровня артериального давления и увеличением мочевой экскрецией маркеров канальцевой дисфункции. 